\title{
THE ESTIMATION OF SMALL QUANTITIES OF ACETONE, ALCOHOL, AND BENZENE IN AIR.
}

By MAJOR ELLIOTT, B.So., F.I.C., and CAPT. J. DALTON, M.C., Dipl. Chem.

(Read at the Meeting, March 5, 1919.)

THE authors were requested to undertake an investigation of the quantity of acetone, alcohol, and benzene in the air of certain factories. As it was found that the amount of the substances would be less than three parts per million by weight in a million volumes of air, the usual methods of absorption and measurement of the diminution of volume were not applicable; therefore it was necessary to draw large quantities of air through various absorbents and determine these by ordinary volumetric methods.

A general account of the impurities of air in factories and workshops has been given in Dr. Legge's translation of “ Ramsboucks' Industrial Poisoning," but methods for the determination of the above substances are not given.

The air was collected as near to the level of the mouths of the operatives as convenient, in order to obtain a sample representative of the air breathed by them, and the time taken to collect the sample was between one and two hours. The air was drawn through the absorbent liquids arranged in parallel by means of Winchester quart bottles fitted with syphons, the amount of water syphoning over giving a measurement of the air drawn through the apparatus.

The apparatus used for the absorption consisted of four narrow measuring cylinders of about 50 c.c. capacity fitted with Folin tubes (J. Bio. Chem., 1912, 11, 493) and rubber stoppers, with one exception, when a cork soaked in paraffin was used. These oylinders were clamped together by means of wooden blocks for convenience in carrying, and were a modification of Drechschmidt's absorbing cylinder referred to in Lunge's "Technical Gas Analysis"; and experiments showed that when the air was drawn through at the rate of about 10 litres an hour, only one cylinder was necessary for complete absorption in each case. Three syphon bottles were connected separately to three of the cylinders by three lengths of tubing 8 to 10 feet long, and this allowed the syphons to remain in a stationary position, while the cylinders could be moved to any desired part of the room. In each case it was found necessary to draw 10 litres of air through the apparatus in order to obtain a sufficient quantity of the vapours for an accurate analysis. 
The absorbent solutions were placed in the cylinders before leaving the laboratory, and the apparatus was carried to the factory in an upright position, no trouble being experienced by splashing of the liquids during the journey. After the collection the cylinders were brought back to the laboratory and the contents transferred to suitable apparatus. This method was found to be very convenient, and obviated the difficulty of fitting up apparatus in the factory. Solutions were chosen which only reacted with the particular substance to be absorbed.

1. The Estimation of Acetone.-Deniges gives a method (Compt. rend., 1898, 126,1868 , and $1898,127,963$ ) by which the acetone is precipitated as a mercuric sulphate compound and weighed as such; the small amounts to be dealt with,

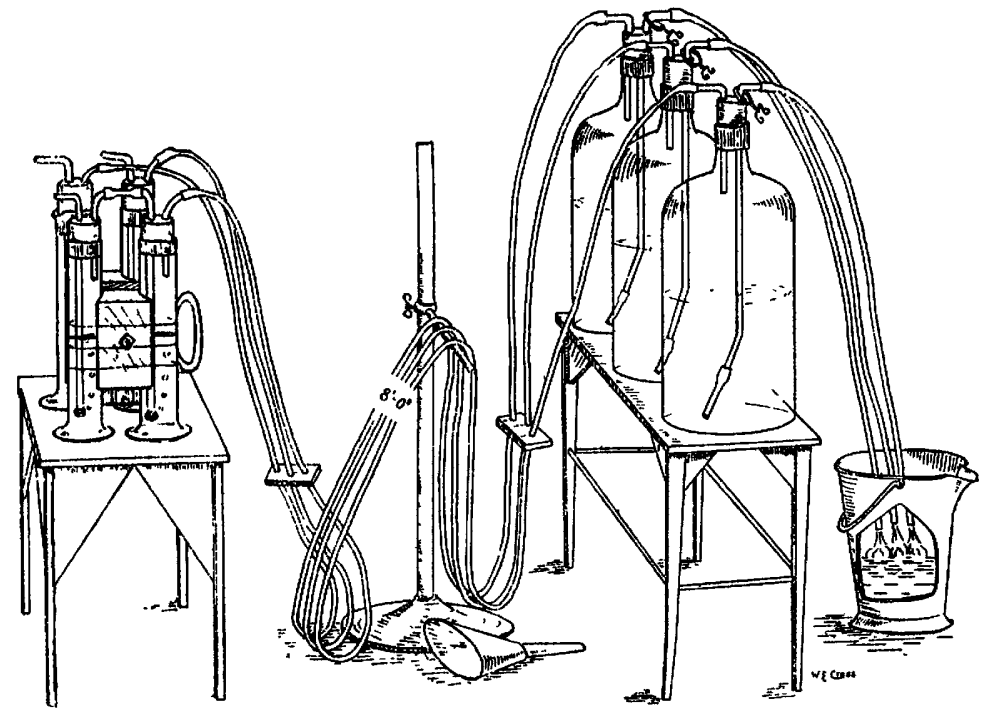

however, precluded this method. But a modification of this method given by Scott Wilson ( $J$. Physiol., 1911, 42, 444; ANalyst, 1911, 36, 548), in which the keto meroury compound is estimated by titration with standard potassium thiocyanate, gave very satisfactory results, and could be used instead of Messinger's method.

Another method (Jolles, Ber., 1906, 39, 1306 ; ANALYst, 1906, 31, 236) consists in the formation of a bisulphite compound with acetone and the titration of the excess of sodium bisulphite, but, owing to the large quantity of air drawn through the solution and the consequent oxidation of the bisulphite, this method was rejected as unsuitable in this case.

Auld (J. Soc. Chem. Ind., 1906, 25, 100 ; AnaLrst, 1906, 31, 235) suggests the use of bromine in potassium bromide for absorption of the acetone, but the large amount of air drawn through, and the consequent loss of bromine, renders this method unsuitable.

The method finally adopted was that of Messinger (J. Soc. Chem. Ind., 1889, 18, 138 ), so largely used in medical work for this purpose. It was considered that the modification suggested by Jitendranath Rakshit (ANALYsT, 1916, 41, 245), in which 
lime-water is used instead of soda, could not be well adapted, owing to the large bulk of lime-water required; and, under the conditions of the experiment, the error due to the formation of iodoform by the alcohol vapour in the air was found to be inappreciable so long as the temperature was kept low.

Twenty-five c.c. of $\frac{\mathbb{N}}{10}$ iodine and 5 e c. of 20 per cent. sodium hydroxide were placed in one of the absorption cylinders of the apparatus, the measured volume of air drawn through, and the excess of iodine titrated back after acidification with $2 \mathrm{~N}$ hydrochloric acid by means of $\frac{\mathrm{N}}{10}$ sodium thiosulphate, starch being used as indicator. One c.c. $\frac{N}{10}$ iodine corresponds to $0.000964 \mathrm{grm}$. of acetone.

As will be seen from the following table, the presence of alcohol can be neglected for all practical purposes :

TABLE A.

\begin{tabular}{|c|c|c|c|c|}
\hline $\begin{array}{c}\text { Amount of Acetone } \\
\text { Tyken. }\end{array}$ & $\begin{array}{l}\text { Amount of Alcohol } \\
\text { Taken. }\end{array}$ & $\begin{array}{c}\text { Difference in c c. } \\
\text { between Blank and } \\
\text { Experiment. }\end{array}$ & $\begin{array}{l}\text { Quantity of } \\
\text { Acetone Found. }\end{array}$ & Error. \\
\hline $\begin{array}{l}0.010 \text { grm. } \\
0.010 \text { grm. } \\
0.0008 \text { grm. }\end{array}$ & $\begin{array}{l}\text { Nil } \\
\text { Nil } \\
\text { Nil }\end{array}$ & $\begin{array}{r}9.8 \text { c.c. } \\
10.0 \text { c.c. } \\
1.0 \text { c.c. }\end{array}$ & $\begin{array}{l}0.0094 \text { grm. } \\
0.0096 \text { grm. } \\
0.0009 \text { grm. }\end{array}$ & $\begin{array}{r}6 \text { per cent. } \\
4 \text { per cent. } \\
11 \text { per cent. }\end{array}$ \\
\hline $\begin{array}{l}\text { Nil } \\
\text { Nil } \\
\text { Nil }\end{array}$ & $\begin{array}{l}0.0104 \text { grm. } \\
0.0052 \text { grm. } \\
0.0026 \text { grm. }\end{array}$ & $\begin{array}{c}0.2 \text { c.c. } \\
0.1 \text { c.c. } \\
\text { Nil }\end{array}$ & $\begin{array}{c}0.00018 \text { grm. } \\
0.00009 \text { grm. } \\
\text { Nil }\end{array}$ & - \\
\hline $\begin{array}{l}0.010 \text { grm. } \\
0.010 \text { grm. } \\
0.010 \text { grm. }\end{array}$ & $\begin{array}{l}0.0026 \mathrm{grm} . \\
0.0052 \mathrm{grm} . \\
0.0104 \text { grm. }\end{array}$ & $\begin{array}{l}9.7 \text { c.c. } \\
9.7 \text { c.c. } \\
9.8 \text { c.c. }\end{array}$ & $\begin{array}{l}0.0093 \text { grm. } \\
0.0093 \text { grm. } \\
0.0094 \text { grm. }\end{array}$ & $\begin{array}{l}7 \text { per cent. } \\
7 \text { per cent. } \\
6 \text { per cent. }\end{array}$ \\
\hline
\end{tabular}

2. The Estimation of Alcohol.-Various methods are given, the basis being the oxidation of aleohol to aldehyde or acetic acid by means of potassium bichromate or permanganate, the excess being titrated.

Benidict and Norris (J.Amer. Chem. Soc., 1890, 12, 302) oxidise to acetic acid and then titrate back the excess of bichromate with ferrous ammonium sulphate.

Argerson (Büll. Soc. Chim., 1902, 18, 302) oxidises to aldehyde, which is distilled over and determined colorimetrically with Schiff's reagent.

Syerbenyi (Zeitsch. Anal. Chem., 1915, 45, 409) titrates back the excess of bichromate iodimetrically after oxidation of the alcohol to acetic acid, and a modification of this method was adopted.

A mixture of 100 c.c. of $\frac{N}{2}$ potassium dichromate, 100 c.c. strong sulphurio acid, and 50 c.c. distilled water, was cooled to normal temperature. Twenty-five c.c. were placed in another absorption cylinder, and the air drawn through, a plug of cottonwool being interposed to prevent access of dust to the bichromate. The liquid was transferred to a flask, the residue being washed in with 45 c.c. of water in order to 
SMALI QUANTITIE $১$ OF ACETONE, ALCOHOL, AND BENZENE IN AIR 135

make up the bulk of the liquid to 70 c.c. Having boiled the solution under a reflux condenser for exactly fifteen minutes and cooled, 100 c.c. of 2 per cent. sodium iodide were added to the mixture, and the liberated iodine titrated with $\frac{\mathrm{N}}{10}$ sodium thiosulphate, using starch as indicator.

After the boiling a faint odour of acetic acid, but none of aldehyde, was detected. A blank experiment was carried out as a control.

Each c.c. of $\frac{N}{10}$ sodium thiosulphate corresponds to $0.00115 \mathrm{grm}$. alcohol. Experiments were made to determine the exact effect of acetone on this estimation, and as will be seen from the following table, no appreciable error was introduced if the proper precautions were adhered to :

TABLE B.

\begin{tabular}{|c|c|c|c|c|}
\hline $\begin{array}{c}\text { Amount of Acetone } \\
\text { Taken. }\end{array}$ & $\begin{array}{c}\text { Amount of Alcohol } \\
\text { Taken. }\end{array}$ & \begin{tabular}{|c|} 
Difference in c.c. \\
between Blank and \\
Experineut.
\end{tabular} & $\begin{array}{l}\text { Quantity of } \\
\text { Alcohol Found. }\end{array}$ & Eiror. \\
\hline $\begin{array}{l}\mathrm{Nil} \\
\mathrm{Nil} \\
\mathrm{Nil}\end{array}$ & $\begin{array}{l}0.0150 \text { grm. } \\
0.0050 \text { grm. } \\
0.0040 \text { grm. }\end{array}$ & $\begin{array}{r}11.5 \text { c.c. } \\
4.3 \text { c.c. } \\
3.5 \text { c.c. }\end{array}$ & $\begin{array}{l}0.0132 \text { grm. } \\
0.0049 \text { grm. } \\
0.0040 \text { grm. }\end{array}$ & $\begin{array}{c}12 \text { per cent. } \\
2 \text { per cent. } \\
\text { Nil }\end{array}$ \\
\hline $\begin{array}{l}0.010 \text { grm. } \\
0.010 \text { grm. } \\
0.020 \text { grm. }\end{array}$ & $\begin{array}{l}\text { Nil } \\
\text { Nil } \\
\text { Nil }\end{array}$ & $\begin{array}{c}0.1 \text { c.c. } \\
\mathrm{Nil} \\
0.3 \text { c.c. }\end{array}$ & $\begin{array}{c}0.0001 \text { grm. } \\
\text { Nil } \\
0.0003 \text { grm. }\end{array}$ & - \\
\hline $\begin{array}{l}0.010 \mathrm{grm} . \\
0.020 \mathrm{grm} .\end{array}$ & $\begin{array}{l}0.0052 \mathrm{grm} . \\
0.0052 \mathrm{grm} .\end{array}$ & $\begin{array}{l}4.5 \text { c.c. } \\
4.6 \text { c.c. }\end{array}$ & $\begin{array}{l}0.0052 \text { grm. } \\
0.0053 \text { grm. }\end{array}$ & $\begin{array}{c}\mathrm{Nil} \\
2 \text { per cent. }\end{array}$ \\
\hline
\end{tabular}

Experiments were carried out in which the alcohol was oxidised to acetic acid by means of pstassium bichromate or potassium permanganate, and after distillation the acid was titrated, but the results were not so satisfactory as in the method adopted. The same applies to a modification of Messinger's method, the solution of alkaline jodide being heated to $60^{\circ} \mathrm{C}$. for several minutes in order to form iodoform.

3. The Estimation of Benzene.-A method is given for the detection of benzene $(J$. Pharn. Chem., 1900, 118, 373) by nitration, reduction, diazotisation, and coupling up the product with $a$-naphthol to form a dye, but was considered more complicated than Pfeiffer's method (Chem. Zeit., 1909, 28, 884), which was finally adopted.

A differential pressure method (Davis and Davis, J. Ind. and Eng. Chem., 1918, 10, 719; ANaurst, 1918, 43,417) seems to give satisfactory results for large quantities of benzene, but the authors considered that the vapour pressure given by the quantities in the air under investigation would be too small for measurement.

The air containing the benzene was passed through 15 c.c. of a mixture of equal volumes of fuming nitric and strong sulphuric acids, contained in the cylinder fitted with a paraffin cork; and the fourth cylinder, containing 20 to 25 c.c. of 20 per cent. 


\section{ESTIMATION OF ACETONE, ALCOHOL, AND BENZENE IN AIR}

sodium hydroxide, was interposed between this cylinder and the syphons, to act as a trap for the acid fumes, and to prevent corrosion of the rubber tubing.

The mixture of acids was beated on the water-bath for about fifteen minutes to ensure complete nitration, cooled, diluted with water, rnade just alkaline to litmus with about 50 c.c. of 40 per cent. sodium hydroxide, and then just faintly acid with dilute hydrochloric acid. After dilution to about 500 c.c. to prevent crystallisation of sodium sulphate, the liquid was extracted with three successive portions of ether, and the ether treated with about 0.5 o.c. caustic soda. After separation of the ether from the soda and distillation, the residue of dinitrobenzene was heated on the waterbath to remove any oxidation products of the alcohol and acetone, and then dissolved in 10 c.c. of alcohol. The alcoholic solution was generally coloured a yellow-brown, and was heated with 10 c.c. of a standardised solution of stannous chloride for ten minutes, and after cooling the excess was titrated back with $\frac{N}{10}$ iodine, using starch as indicator. A blank experiment was carried out as a control. Each c.c. of $\frac{N}{10}$ iodine corresponds to $0.00065 \mathrm{gr}$. benzene.

TABLe C.

\begin{tabular}{|c|c|c|c|c|c|}
\hline Substance Taken. & $\underset{\text { Experiment. }}{\text { Blank }}$ & Experiment. & Difference. & $\begin{array}{l}\text { Quantity } \\
\text { Found. }\end{array}$ & $\begin{array}{c}\text { Quantity } \\
\text { Taken }\end{array}$ \\
\hline \multirow[b]{2}{*}{ Benzene } & \multicolumn{3}{|c|}{ c.c. of $\frac{\mathrm{N}}{10}$ Iodine. } & & \\
\hline & $\begin{array}{l}16 \cdot 8 \\
16 \cdot 8 \\
16 \cdot 8\end{array}$ & $\begin{array}{l}14 \cdot 6 \\
14 \cdot 2 \\
14 \cdot 2\end{array}$ & $\begin{array}{l}2 \cdot 2 \\
2 \cdot 6 \\
2 \cdot 2\end{array}$ & $\begin{array}{l}000143 \\
0.00169 \\
0.00169\end{array}$ & $\begin{array}{l}0.00167 \\
0.00167 \\
0.00167\end{array}$ \\
\hline
\end{tabular}

The following figures indicate the amount of these substances per million c.c. of air found in the factories :

\begin{tabular}{llll|l|l|l}
\hline & & & & Acetone. & Alcohol. & Benzene. \\
\hline Minimum & $\ldots$ & $\ldots$ & $\ldots$ & 0.02 & Grms. & Grms. \\
Maximum & $\ldots$ & $\ldots$ & $\ldots$ & 1.86 & 0.02 & 0.01 \\
Mean ... & $\ldots$ & $\ldots$ & $\ldots$ & 0.31 & 3.00 & 0.90 \\
& & & & & 0.65 & 0.26 \\
\hline
\end{tabular}

R. A.M. COLIEGE,

Millbank. 